\title{
A Novel Survey to Examine the Rela- tionship between Health IT Adoption and Nurse-Physician Communication
}

A Jay Holmgren ${ }^{1,2}$; Eric Pfeifer ${ }^{1,2}$; Milisa Manojlovich ${ }^{3}$; Julia Adler-Milstein ${ }^{1,2}$

${ }^{1}$ School of Information, University of Michigan, Ann Arbor, Ml; ${ }^{2}$ School of Public Health, University of Michigan, Ann Arbor, Ml; ${ }^{3}$ School of Nursing, University of Michigan, Ann Arbor, MI

\section{Keywords}

Electronic health records and systems, inpatient CPOE, provider-provider, hospital information systems, communication

\section{Summary}

Background: As EHR adoption in US hospitals becomes ubiquitous, a wide range of IT options are theoretically available to facilitate physician-nurse communication, but we know little about the adoption rate of specific technologies or the impact of their use.

Objectives: To measure adoption of hardware, software, and telephony relevant to nurse-physician communication in US hospitals. To assess the relationship between non-IT communication practices and hardware, software, and telephony adoption. To identify hospital characteristics associated with greater adoption of hardware, software, telephony, and non-IT communication practices. Methods: We conducted a survey of 105 hospitals in the National Nursing Practice Network. The survey captured adoption of hardware, software, and telephony to support nurse-physician communication, along with non-IT communication practices. We calculated descriptive statistics and then created four indices, one for each category, by scoring degree of adoption of technologies or practices within each category. Next, we examined correlations between the three technology indices and the non-IT communication practices index. We used multivariate OLS regression to assess whether certain types of hospitals had higher index scores.

Results: The majority of hospitals surveyed have a range of hardware, software, and telephony tools available to support nurse-physician communication; we found substantial heterogeneity across hospitals in non-IT communication practices. More intensive non-IT communication was associated with greater adoption of software $(r=0.31, p=0.01)$, but was not correlated with hardware or telephony. Medium-sized hospitals had lower adoption of software $(r=-1.14, p=0.04)$ in comparison to small hospitals, while federally-owned hospitals had lower software $(r=-2.57, p=0.02)$ and hardware adoption $(r=-1.63, p=0.01)$.

Conclusions: The positive relationship between non-IT communication and level of software adoption suggests that there is a complementary, rather than substitutive, relationship. Our results suggest that some technologies with the potential to further enhance communication, such as CPOE and secure messaging, are not being utilized to their full potential in many hospitals. 
Correspondence to:

A Jay Holmgren

105 S State St

Ann Arbor, MI 48103

Email: ajholmgr@umich.edu
Appl Clin Inform 2016; 7: 1182-1201

https://doi.org/10.4338/ACI-2016-08-RA-0145

received: August 23, 2016

accepted: November 4, 2016

published: December 21, 2016

Citation: Holmgren AJ, Pfeifer E, Manojlovich M, Adler-Milstein J. A novel survey to examine the relationship between health IT adoption and nurse-physician communication. Appl Clin Inform 2016; 7:

1182-1201

https://doi.org/10.4338/ACI-2016-08-RA-0145

Funding

This project was supported by grant number R01 HS022305 from the Agency for Healthcare Research and Quality. The content is solely the responsibility of the authors and does not necessarily represent the official views of the Agency for Healthcare Research and Quality. 


\section{Background \& Significance}

\subsection{Background}

The Health Information Technology for Economic and Clinical Health (HITECH) Act seeks to promote widespread adoption of health information technology (HIT) in order to address persistent quality and efficiency challenges facing our healthcare delivery system, many of which derive from reliance on paper records [1]. HIT includes a variety of tools that clinicians can use to communicate with each other either directly (e.g., email) or indirectly (e.g., shared record, computerized provider order entry with work queues), which supplement existing communication technologies such as pagers and phones. However, there is growing recognition of the unintended consequences of HIT adoption [2], particularly on nurse-physician communication [3, 4]. Increasing use of HIT is likely to affect communication between nurses and physicians [5] because nurses and physicians who previously came together at the point-of-care to discuss a patient face-to-face may now rely on these technologies to mediate their communication [6]. Poor communication between physicians and nurses is well known as one of the most common causes of adverse events for hospitalized patients [7]. It is therefore critically important to better understand how HIT and communication technologies are facilitating or hindering nurse-physician communication [8].

An important starting point is simply to capture the range of information and communication technologies that are in place in hospitals. While substantial effort has focused on tracking hospital adoption of electronic health records (EHRs) and computerized provider order entry (CPOE) [9], we know less about the other types of communication technologies that are available in hospitals. Further, it is critical to assess the relationships between the degree of adoption of information and communication technologies and nurse-physician communication practices. This is because they might work as substitutes, where communication using the information technology resource replaces or dampens the need for traditional, face-to-face communication. Alternatively, they may be complementary, such that health IT works as a supplemental tool and serves to promote the overall level of communication by maintaining or increasing the existing level of non-technology based communication. It is also possible that health IT impedes communication in ways that create the need for additional communication to resolve confusion or ambiguity. Finally, it is important to assess whether certain hospital characteristics affect degree of adoption. For example, hospital type may be a proxy for resource availability. It may be that some organizational decisions, such as selecting an EHR from a single vendor versus using modules from multiple vendors, as well as some hospital characteristics, such as size [10] or teaching status [11], impact the extent of adoption of communication-relevant technologies as well as non-IT communication.

\subsection{Theoretical Framework}

Our study used a conceptual model developed in our previous work that explored how communication practices and work relationships create the context in which health information technologies designed to facilitate communication are situated ( $>$ Figure 1) [8]. The model, based on a review of the literature, posits that communication practices and work relationships mediate the relationship between communication technology and communication. That is, communication practices and work relationships help explain how communication technology affects communication, because the use of communication technology does not occur in a vacuum. The current study focuses exclusively on the interplay between communication practices and technology adoption.

Our theoretical model highlights two communication practices in particular that are important to understanding how communication technology has its impact on communication: the use of rich media and location and availability of computers. In the hospital environment, complex, ambiguous clinical issues frequently demand detailed information and require rich methods of communication, such as synchronous, face-to-face physician-nurse dialogue for successful resolution. Previous work has shown that computer applications such as EHRs and CPOE systems do not provide the rich, synchronous communication necessary in those complex care instances $[12,13]$. Location and availability of computers are important considerations because when physicians and nurses are dispersed and relying on technology to communicate, there are fewer opportunities for building a 
frame of reference and sharing knowledge from different perspectives, and the meaning of a complex message may be more easily misinterpreted, leading to potentially suboptimal care [14].

\section{Objectives}

Given our interest in developing a deeper understanding of how communication practices (the use of rich media, and location and availability of computers) affect the relationship between communication technology and communication, we seek to address three research questions:

1. What is the level of adoption of types of hardware, software, and telephony used to facilitate nurse-physician communication? And to what extent are non-IT mediated forms of nurse-physician communication occurring?

2. Is there a relationship between the extent of non-IT mediated communication practices and hardware adoption, software adoption, and telephony adoption?

3. What types of hospitals are more likely to have greater adoption of hardware, software, telephony, and non-IT communication practices?

\section{Methods}

\subsection{Population Studied}

We studied medical-surgical units in US acute-care hospitals. We chose this setting because little is known about communication on medical-surgical units and most inpatient care is provided there. Our sampling frame was comprised of all 105 members of the National Nursing Practice Network (NNPN), a national consortium of U.S. hospitals focused on implementing evidence-based nursing practices [15].

\subsection{Survey Development and Administration}

We developed a survey to identify health information and communication technologies in use on medical-surgical units, along with non-IT mediated communications practices. The selection of survey questions was guided by our theoretical framework to identify the variety of communication media (including communication technologies) that may interfere or assist with physician-nurse communication in each hospital. Where existing instruments included questions of interest, we incorporated them into our survey (e.g., questions on EHR adoption came from the American Hospital Association (AHA) IT Supplement). For questions on availability and use of other types of technologies (e.g., pagers, cell phones, tablets), as well as questions on computer-mediated communication between physicians and nurses, we did not find suitable questions from existing instruments and therefore developed new ones. The survey consisted of 99 total questions and was divided into seven sections: overall HIT adoption, computer hardware, physician and nurse use of computers, infrastructure for electronic communication (i.e., pagers and electronic white boards), nurse and physician use of electronic communication technologies, non-electronic ways of communicating, and demographics. Questions included both availability of technology and extent of use. Some questions had a range of possible responses (e.g., all, some, few, none) whereas others had dichotomous answer choices (e.g., do nurses use cellular telephones for work-related purposes?).

The preliminary survey instrument was pilot tested in a two-step process. First, two academic researchers and one healthcare informatician individually talked through the survey with the principal investigator (MM), to make sure that the survey questions aligned with the theoretical model and to establish face validity. Based on feedback, the survey was refined and then pilot tested with a small group ( $\mathrm{n}=7$ ) of informaticians, hospital leaders (a physician and nurses), and survey experts, further establishing face validity of the instrument and resulting in additional refinements. In pilot testing, the survey took 10 to 20 minutes to complete. After pilot testing, the survey was programmed into REDCap, a web-based electronic data capture (EDC) system that is secure, and HIPAA compliant. 
The Chief Nurse Executive at each hospital in the sample was invited by postal letter to participate in the survey. The postal mail letter was the first of four contacts that introduced the study and included a survey link with a personal access code that was assigned to each respondent. The use of personal access codes allowed the respondent to complete the survey without further contact, prohibited the same respondent from completing the survey more than once, and allowed us to link a particular survey with a specific hospital. Accompanying the letter was a "fact sheet" highlighting advantages to participation as well as a \$20 gift card as an advance incentive to complete the survey. The Chief Nurse Executive was instructed to work with an informatician, physician, or other appropriate personnel as needed to complete the survey. Email requests to complete the online survey were sent within a week of sending the postal mail letter, along with a study fact sheet, and again about a week after that. The final contact consisted of follow-up telephone calls to administrative assistants or Chief Nurse Executives themselves. The data collection process lasted from May 4, 2015 to July 31, 2015. Seventy-four hospitals provided complete data for analysis (70\% response rate). In testing for respondent bias, we found no significant differences between respondents and non-respondents on the following hospital characteristics: region, federal government, public, for-profit, non-profit, church-affiliated, urban/rural, academic medical center, bed size (Data not shown).

\subsection{Measures}

\section{Hardware, Software, Telephony, and Non-IT Communication Practice Adoption}

We first calculated descriptive statistics for questions related to three individual types of communication-related hardware that are available for use by physicians and by nurses:

1. stationary computers;

2. portable computers and

3. tablet computers.

We then calculated descriptive statistics for the extent to which four types of software are used to facilitate communication between nurses and physicians:

1. Email within EHR;

2. Email separate from EHR;

3. Middleware (software that enables communication between an operating system and applications in a distributed computing system, such as smart phone apps that let physicians know nurse staff assignments for a shift, or that send patient alarms to physician and/or nurse smart phones); and

4. CPOE (split out based on whether nurses receive notification when an order has been placed and whether physicians use $\mathrm{CPOE}$ as a way to communicate with nurses).

Next, descriptive statistics were calculated to determine use of telephony: nurse assignment to individual telephones, nurse and physician use of cellular telephones, and nurse and physician use of pagers. Finally, we calculated descriptive statistics for non-IT communication practices: the extent to which nurses and physicians engage in face-to-face communication in general, as well as three particular forms:

1. verbal orders;

2. nurses communicate with a physician extender before contacting a physician, and

3. bedside nurses participate in rounds.

\section{Indices}

To capture overall level of adoption of each category of technology as well as non-IT communication practices, we created four indices by grouping the questions detailed above into the four categories. We classified the first three categories (hardware, software, telephony) as technology indices. We scored responses to each question from 0 to 1 , with 1 indicating more of whatever was being measured. We scored individual question responses in line with the perceived value of the adoption of that particular technology or communication practice. For example for level of EHR adoption, a basic EHR without clinician notes was scored as a 0.0, a basic EHR with clinician notes was scored as 0.5 , and a comprehensive EHR was scored as a 1.0. We strove to be consistent with our scoring sys- 
tem. For example, when scoring questions related to software adoption, such as use of email inside or outside of the EHR system, answers of "Never/Rarely" were scored as 0.0 while answers of "Sometimes" or "Regularly" were scored as a 1.0. Similarly for other questions using "Never" to "Regularly" categories, we first dichotomized responses into "Never/Rarely" and "Sometimes/Regularly" then assigned scores of 0 or 1 respectively. We summed responses within each index to capture which hospitals had comparatively less or more adoption in each domain, and then examined the correlations among the three technology indices and the fourth (non-IT communication) index. ( $\triangleright$ Appendix Table 1 has individual questions and associated scoring.)

\section{Hospital Characteristics}

We selected a subset of hospital characteristics that we hypothesized might be related to the index scores. These included size (small: $<100$ beds, medium: 100-500 beds, large: $>500$ beds), teaching status (hospitals with approval to participate in residency and/or internship training by the Accreditation Council for Graduate Medical Education, or hospitals who are a member of the Council of Teaching Hospitals (COTH) of the Association of American Medical Colleges), urban/rural location, hospital ownership (private/non-profit, private/for-profit, non-federal/public, federal/public), and participation in payment reform programs (an Accountable Care Organization (ACO) [16] and/or patient-centered medical home (PCMH) [17]). We also included 4 information technology factors: having at least a "basic" EHR system (which requires adoption of 10 functionalities and is more advanced than an EHR that has met federal certification standards [18]), using a single EHR vendor, having advanced interoperability capabilities (using the ONC definition of ability to find, send, receive and integrate data from external organizations [19]), and participating in a Regional Health Information Exchange.

The measures of hospital characteristics were created from the American Hospital Association Annual Survey and the AHA Annual Survey - IT Supplement data for 2014 [20]. The survey is sent to the Chief Executive Officer (CEO) of every hospital in the United States, and he or she is asked to complete it or delegate completion to a knowledgeable person in the organization. Non-respondents receive multiple follow-up phone calls and mailings to achieve a high response rate. The 2014 survey was fielded between November 2014 and February 2015, was sent to 6,377 hospitals, and received 3,307 responses. The AHA survey data was linked to our survey results using each hospital's unique AHA identification number. The seventy-four hospitals who responded to the survey serve as the analytic sample for our descriptive statistics and indices. The forty-eight hospitals that provided complete data in our survey and also responded to the 2014 AHA Annual Survey - IT Supplement were the analytic sub-sample for our bivariate means comparison and multivariate regression model.

\subsection{Analytic Approach}

For research question 1, we present descriptive statistics across all 74 survey respondent hospitals for measures described above related to hardware, software, telephony, and non-HIT nurse-physician communication. For research question 2, we examined correlations between the four indices. For research question 3, we used the sub-sample of 48 hospitals who responded to the AHA IT survey and examined bivariate and multivariate relationships between each index and hospital characteristics. The bivariate results were generated by running two-tailed t-tests with unequal variances. In order to more robustly assess the relationships between hospital characteristics and index scores, we performed ordinary least squares multivariate regression analysis with the same hospital characteristics.

\section{Results}

For the three types of hardware examined, stationary computers were in widespread use and used equally by physicians and nurses ( $\triangleright$ Figure 2 ). Ninety-seven percent of hospitals reported that physicians had access to stationary computers, with $99 \%$ reporting nurses had access to those computers. Portable computers were adopted less often, and were used more often by nurses than by physicians 
(in $81 \%$ of hospitals and $64 \%$ of hospitals, respectively). Tablets were rarely adopted, with $11 \%$ of hospitals reporting physician use and $4 \%$ of hospitals reporting nurse use.

Only 7\% of hospitals reported that email within the EHR was used regularly in nurse-physician communication, and 9\% reported regular use of email separate from the EHR, while 16\% of hospitals reported regular use of middleware. ( Figure 3) Physicians used CPOE as a way to communicate with nurses regularly in $20 \%$ of hospitals (and sometimes in an additional $47 \%$ of hospitals). In $77 \%$ of hospitals, nurses were alerted when an order had been entered into the electronic health record.

In the majority of hospitals (53\%), more than three-quarters of nurses had individual phones, and nurses had cell phones in $51 \%$ of hospitals. In comparison, physicians had cell phones in $69 \%$ of hospitals ( $>$ Figure 4 ). As compared to physicians who often carry pagers ( $>75 \%$ of physicians in $62 \%$ of hospitals), nurses carried pagers less often ( $<25 \%$ of nurses in $82 \%$ of hospitals).

In the majority of hospitals (76\%), nurses used face-to-face communication with physicians "All the Time" while $20 \%$ of hospitals reported nurses used face-to-face communication "Regularly," with "Sometimes" and "Rarely" at 1\% each ( Figure 5). This is similar to physicians, who used face-toface communication: "All the Time" in $76 \%$ of hospitals, "Regularly" in 19\% of hospitals, "Sometimes" in $3 \%$ of hospitals, and "Rarely" in $1 \%$ of hospitals. There was substantial variation across hospitals in the extent to which physicians gave verbal orders to nurses ("All the Time" in 9\% of hospitals, "Regularly" in 22\% of hospitals, "Sometimes" in 34\% of hospitals, and "Rarely" in 32\% of hospitals), the extent to which nurses communicated with a physician extender before contacting a physician ("All the Time" in $27 \%$ of hospitals, "Regularly" in 32\% of hospitals, "Sometimes" in 20\% of hospitals, and "Rarely" in $18 \%$ of hospitals), and the extent to which bedside nurses participated in rounds ("All the Time" in 49\% of hospitals, "Regularly" in 23\% of hospitals, "Sometimes" in 20\% of hospitals, and "Rarely" in 7\% of hospitals).

When we calculated index scores in each of the four domains, the computer hardware index had a mean score of 7.48 (SD 1.77, range $3.75-11.5$ ) and a Coefficient of Variation of $23.7 \%$. The software index mean score was 6.22 (SD 1.25, range 2.5 - 9) with a Coefficient of Variation of $21.3 \%$. The telephony index had a mean score of 3.03 (SD 1.08, range 0.5 - 5.5) with a Coefficient of Variation of $36.4 \%$. The communication practices index mean score was 4.92 (SD 1.26, range $1.5-7$ ) with a Coefficient of Variation of $25.6 \%$. The communication practices index was significantly positively correlated with software $(r=0.31, p<0.01)$ but not hardware $(r=0.09, p=0.44)$ or telephony $(r=0.06, p=0.61)$.

We found that hardware, software, telephony, and communication index scores were associated with key hospital characteristics. In bivariate results, we found that federal hospitals had lower mean scores on the hardware index in comparison to private/ non-profit hospitals (5.50 for federal hospitals compared to 7.92 for private/ non-profit hospitals, $p=0.01$ ). Hospitals that had all four core interoperability capabilities had a higher mean hardware score than those that did not ( 8.00 vs $6.98, p$ $=0.05)$. Characteristics associated with the software index included whether or not the hospital had at least a basic EHR system (6.30 for hospitals with basic EHR vs 5.67 for hospitals with less than basic EHR, $p=0.02$ ) and size (7.07 for hospitals with over 500 beds vs 5.97 for hospitals with 100 500 beds, $p=0.04$ ). In terms of the telephony index, large hospitals were more likely than medium or small hospitals to have a higher index value (3.79 for large hospitals compared to 2.86 for mediumsized hospitals, $p=0.03$ ). For non-IT communication, hospitals located in urban areas compared to those in rural areas had a higher score (5.23 for urban vs 4.44 for rural, $p=0.03$ ) as did hospitals with at least a basic EHR system $(5.27$ vs $3.75, p<0.01)$.

In multivariate models, federal hospitals had lower hardware and software index scores, (coefficient $=-2.57,-1.63, p=0.02,0.01$, respectively) ( $>$ Table 2 ). Medium sized hospitals had a lower software index score (coefficient $=-1.14, p=0.04$ ). No characteristics were significantly associated with the telephony and communication practice indices.

\section{Discussion}

In a recent survey of medical-surgical units, we captured the extent of adoption of various information and communication technologies used to support nurse-physician communication. While we 
found a lot of consistency in the types of health IT and communications technology adopted across hospitals, we found varied rates of adoption by type of technology. Stationary computers were widely adopted while tablet computers were rarely adopted; $\mathrm{CPOE}$ was widely used for communication while email as well as middleware were rarely adopted; and pagers among physicians were widely adopted while pagers among nurses were not. There was also substantial heterogeneity in non-IT communication practices across hospitals, and we found that it was positively correlated with the software adoption index. In the context of our theoretical framework, this suggests that greater IT-enabled communication capabilities do not come at the expense of rich, synchronous non-IT communication such as face to face dialogue. However, it is also possible that having more software impairs the quality of communication, creating the need for more face-to-face communication to clarify meaning. An essential next step is to determine causality and whether different combinations of technology have implications for the quality of communication and ultimately care.

Our technology index - not dependent on a specific electronic health record system or technology type - allowed us to compare level of communication practices with adoption of three categories of technologies. By gathering more detail about the type, amount, location, and use of technology, important nuances emerged. For example, despite the widespread availability of stationary computers to both nurses and physicians, comparatively little communication takes places via email within or outside of EHR systems. In contrast, the majority of hospitals reported that nurses regularly receive notifications from the computer system to alert them to a new order being placed. This suggests that much of the communication taking place via software is physicians placing orders and nurses filling them, rather than back-and-forth dialogue. This is consistent with our theoretical framework that suggests that IT-enabled communication is primarily useful for routine, simple tasks such as order placement, and is not a suitable replacement for synchronous face-to-face communication.

Our results examining differences in the indices based on hospital characteristics also revealed interesting insights. For both hardware and software, federally-owned hospitals had lower adoption, which could reflect resource constraints in those settings. However, there was no relationship with communication practices and so it does not appear that the lack of technology is resulting in more or less intensive communication in federally-owned hospitals. The fact that medium-sized hospitals had lower software adoption in comparison to large hospitals also likely reflects the resource constraints in smaller settings, as well as the need for additional software to manage the more complex patient mix in larger hospitals. Finally, the fact that hospitals in urban settings had a lower communication index suggests that these hospitals may have different relationships between nurses and physicians, perhaps due to different staffing models or differences in the types of providers who work in these settings. While it did not appear that these were a result of differences in technology, it is still possible that the same types of technology are used in ways that interfere with effective communication.

Our evaluation of the effect of health information technology on nurse-physician communication contributes to a growing body of literature evaluating the adoption of these technologies and their impact on provider workflow, communication, and job satisfaction. As EHR adoption in US hospitals becomes ubiquitous [10], a wide range of IT options such as secure messaging, email, and CPOE are theoretically available to facilitate physician-nurse communication, but we know little about the adoption rate of specific technologies or the impact of their use. Recent studies have found many physicians are low-frequency users of CPOE when it is available [21], and our findings confirm that only $16 \%$ of hospitals report that physicians use $\mathrm{CPOE}$ "regularly" to communicate orders to nurses. Additionally, while evidence suggests that secure messaging through EHRs, especially via mobile solutions, can be an effective way to facilitate communication between members of clinical care teams [22], our results show that adoption of these technologies is far from widespread. Considering the significant potential for features such as $\mathrm{CPOE}$ and secure messaging to improve communication [23], the lack of frequent use when available suggests that they need improvement.

However, what constitutes a useful communication technology tool may vary by clinical role, and prior literature suggests that nurses have faced particular challenges. A 2013 study by Keenan, et. al., found that effective communication between nurses and other health care team members, such as physicians, was one of three major areas of concern nurses expressed regarding retrieving, documenting, and communicating patient information [24]. This may be explained by the fact that, in a 
separate study, nurses indicated a preference to integrate their EHR systems more closely to bedside care [25], and our results show that adoption of mobile devices that can accomplish this goal, such as laptops and tablets, lags behind stationary computers. Thus, our study reveals a likely gap between the technologies nurses perceive as helpful to facilitate communication and what hospitals are actually adopting.

Our study has important limitations. We undertook a cross-sectional survey and so we are only able to capture adoption at a single point in time and examine associations. Because we had a single respondent from each hospital, they were not able to capture heterogeneity within their medical-surgical unit on the measures of interest and may have reported in error if they were not sufficiently familiar with experiences on the frontlines of care. However, we did ask respondents to reach out to others in their organization who would be best positioned to answer our questions. We also examined a relatively small sample of hospitals and it is therefore unclear the extent to which our findings generalize to all hospitals. Since we surveyed only hospitals in the National Nursing Practice Network, our findings may not be generalizable to other hospitals - NNPN hospitals are dedicated to implementing evidence-based nursing practices and may have more advanced communication practices and / or more comprehensive IT adoption as a result. Our study utilizes a new survey instrument, though it was discussed with experts to establish face validity and several of the individual questions came from a well-established survey instrument (the AHA Annual Survey IT supplement, which has been tested for reliability and validity [20]). We did not conduct an internal reliability analysis, instead choosing to aggregate individual responses into the indices, which is consistent with our theoretical framework that examines the relationship between technology and communication practices. Finally, while we scored the indices consistently and relative to the perceived value of each response, others may have different perceptions of the value of certain technologies and communication practices, which could alter the results.

\section{Conclusion}

Given the proliferation of health information and communication technologies, characterizing adoption alongside communication practices in a detailed way is an essential first step towards developing interventions [26], policies, or practices to promote effective nurse-physician communication. Our results offer insights into where there is variation across hospitals, and how the extent of adoption in three technology domains - hardware, software, and telephony - relates to non-IT communication practices. The specific hospitals characteristics that we identify guide future work in this domain by revealing where the relationship between technology and nurse-physician communication may differ.

\section{Clinical Relevance Statement}

Our research examines the relationship between the extent of adoption of information and communication technologies and non-IT physician-nurse communication practices. Our findings show that higher levels of software adoption are associated with more intense non-IT communication practices. This suggests that health IT is a complementary tool in physician-nurse communication, rather than a substitutive one, but whether it is helping or simply causing the need for additional communication is unclear.

\section{Conflict of Interest}

Julia Adler-Milstein is on the technical advisory board of QPID Health, Inc.

\section{Protection of Human and Animal Subjects}

Received Institutional Review Board approval at the University of Michigan under eResearch ID number "HUM00092942." 


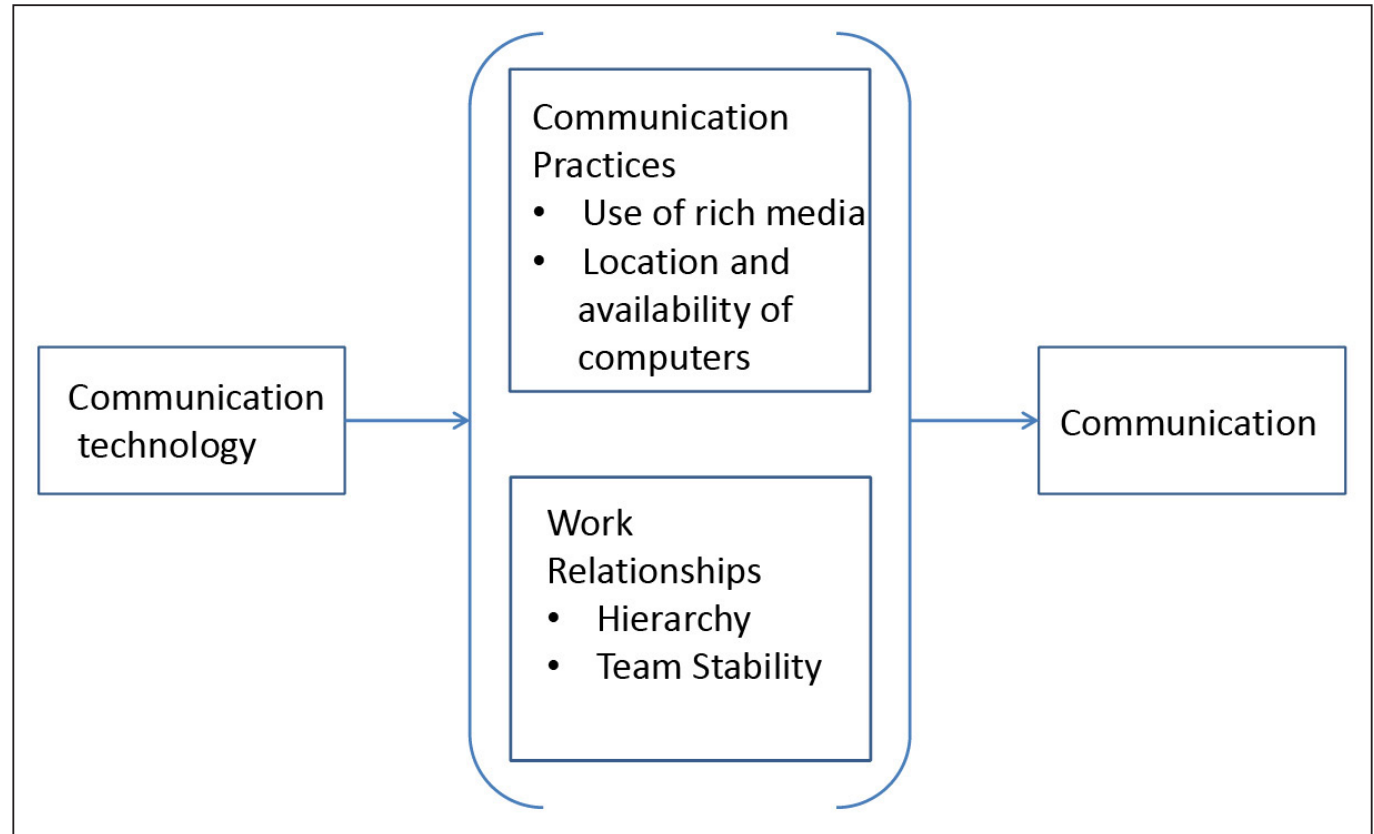

Fig. 1 Theoretical Model

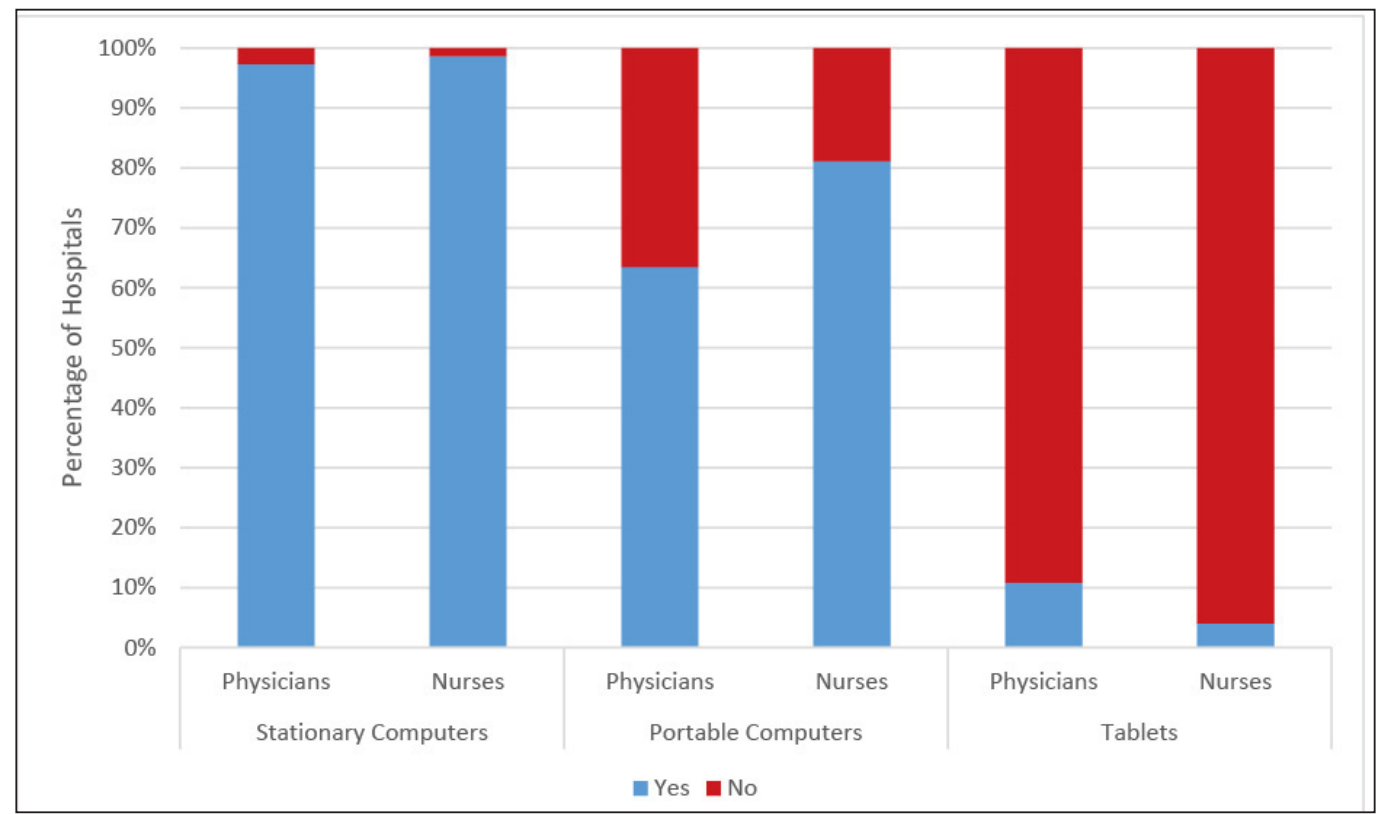

Fig. 2 Hardware by Physician and Nurse Usage 


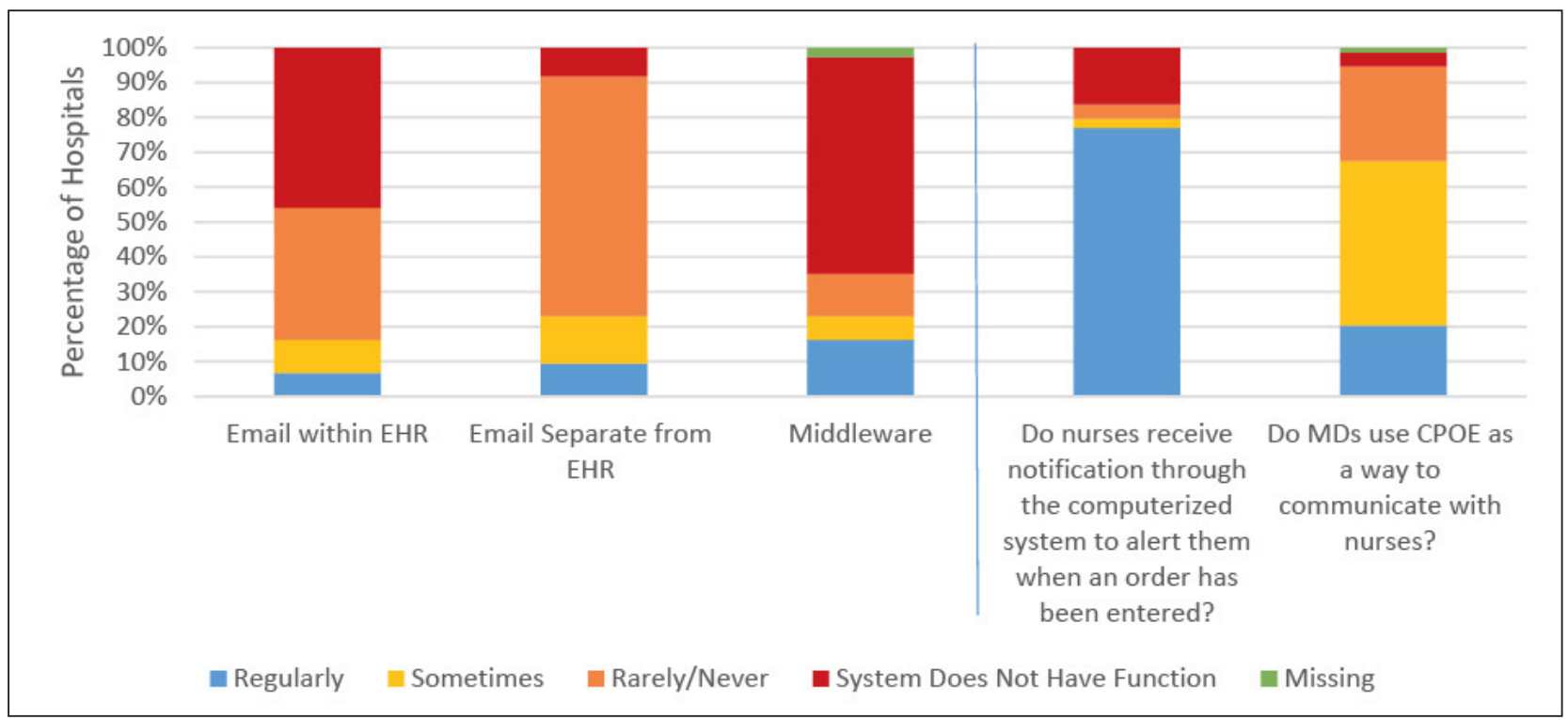

Fig. 3 Use of Software to Facilitate Communication between Nurses and Physicians

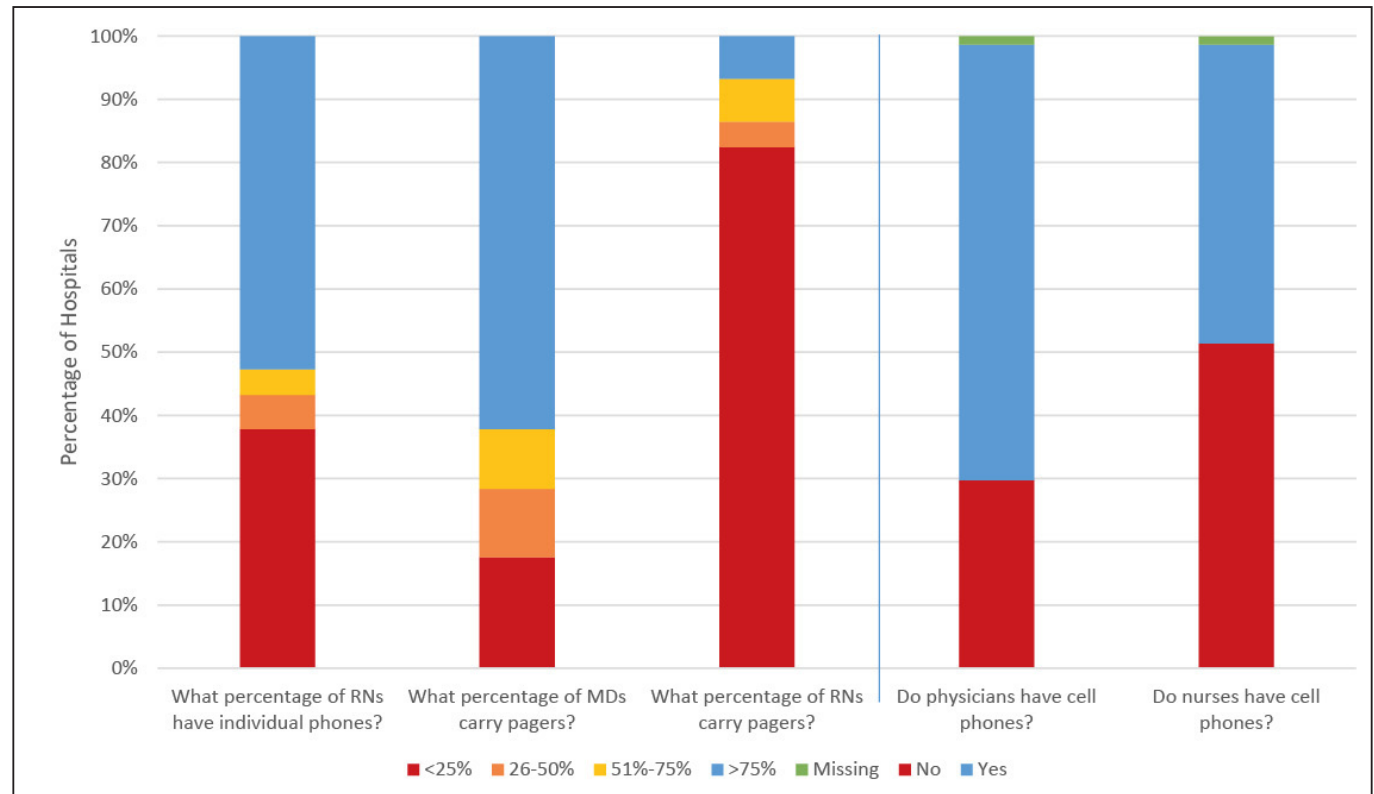

Fig. 4 Telephonic Communication between Nurses and Physicians 


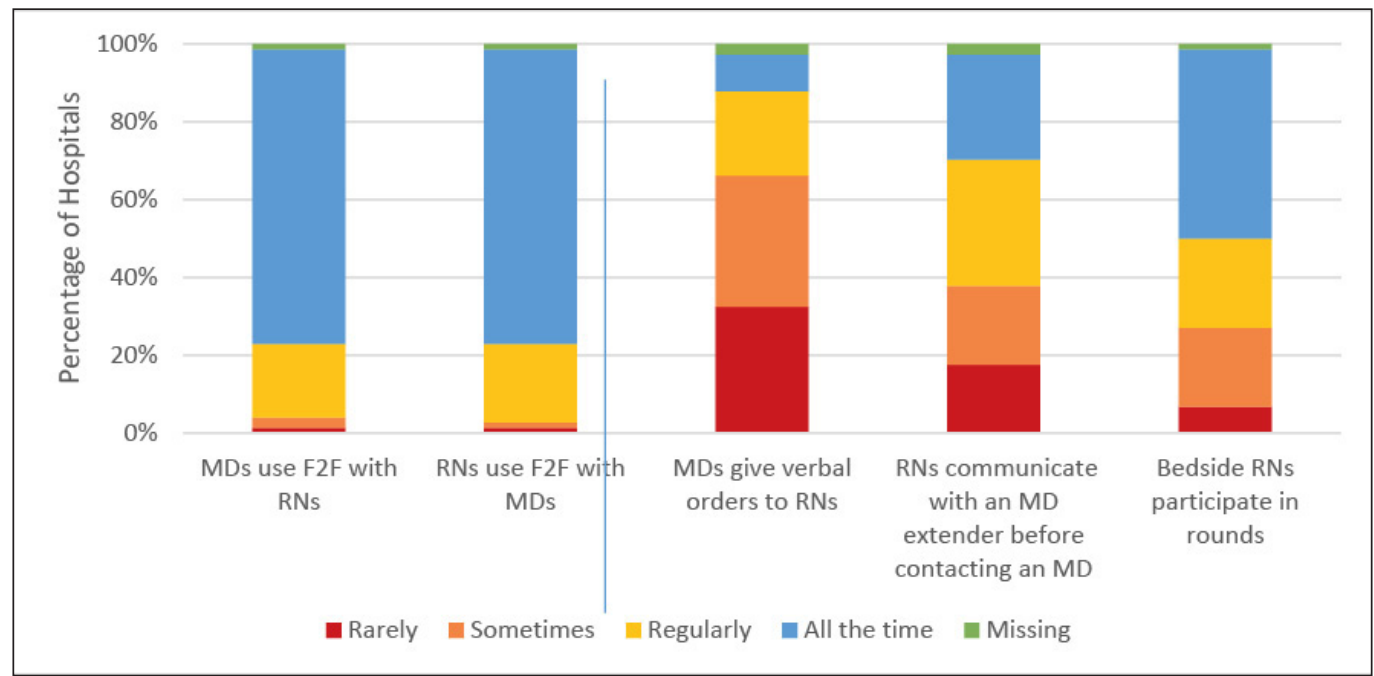

Fig. 5 Non-Electronic Communication between Nurses and Physicians 
Table 1 Statistically Significant Bivariate Relationships between Hospital Characteristics and Four Indices: Hardware, Software, Telephony, and Communication Practices

\begin{tabular}{|c|c|c|c|c|c|}
\hline & $\begin{array}{l}\text { Index Mean } \\
\text { Without } \\
\text { Characteristic }\end{array}$ & $\begin{array}{l}\text { Observations } \\
\text { Without } \\
\text { Characteristic }\end{array}$ & $\begin{array}{l}\text { Index Mean } \\
\text { With } \\
\text { Characteristic }\end{array}$ & $\begin{array}{l}\text { Observations } \\
\text { With } \\
\text { Characteristic }\end{array}$ & $p$-value \\
\hline \multicolumn{6}{|l|}{ Hardware Index } \\
\hline $\begin{array}{l}\text { Hospitals with advanced in- } \\
\text { teroperability capabilities } \\
\text { (Finding, Sending, Receiv- } \\
\text { ing, and Integrating Data) }\end{array}$ & 6.98 & 25 & 8.00 & 23 & 0.05 \\
\hline $\begin{array}{l}\text { Federal Hospitals (vs Pri- } \\
\text { vate/Non-Profit Hospitals) }\end{array}$ & 7.92 & 38 & 5.50 & 6 & 0.01 \\
\hline \multicolumn{6}{|l|}{ Software Index } \\
\hline $\begin{array}{l}\text { Hospitals over } 500 \text { beds (vs } \\
\text { Hospitals with } 100-500 \\
\text { beds) }\end{array}$ & 5.97 & 36 & 7.07 & 7 & 0.04 \\
\hline $\begin{array}{l}\text { Having at least a basic EHR } \\
\text { system }\end{array}$ & 5.67 & 6 & 6.30 & 42 & 0.02 \\
\hline \multicolumn{6}{|l|}{ Telephony Index } \\
\hline $\begin{array}{l}\text { Hospitals over } 500 \text { beds (vs } \\
\text { Hospitals with } 100-500 \\
\text { beds) }\end{array}$ & 2.86 & 36 & 3.79 & 7 & 0.03 \\
\hline \multicolumn{6}{|l|}{$\begin{array}{l}\text { Communication Practices } \\
\text { Index }\end{array}$} \\
\hline $\begin{array}{l}\text { Having at least a basic EHR } \\
\text { system }\end{array}$ & 3.75 & 6 & 5.27 & 42 & $<0.01$ \\
\hline $\begin{array}{l}\text { Hospitals located in an } \\
\text { urban setting }\end{array}$ & 4.44 & 9 & 5.23 & 39 & 0.03 \\
\hline
\end{tabular}


Table 2 Multivariate Regression Results Assessing the Independent Relationships between Hospital Characteristics and Four Indices: Hardware, Software, Telephony, and Communication Practices

\begin{tabular}{|c|c|c|c|c|c|c|c|c|}
\hline & \multicolumn{2}{|c|}{ Hardware Index } & \multicolumn{2}{|c|}{ Software Index } & \multicolumn{2}{|c|}{ Telephony Index } & \multicolumn{2}{|c|}{$\begin{array}{l}\text { Communication } \\
\text { Practices Index }\end{array}$} \\
\hline & $\begin{array}{l}\text { Coeffi- } \\
\text { cient }\end{array}$ & $p$-value & $\begin{array}{l}\text { Coeffi- } \\
\text { cient }\end{array}$ & $p$-value & $\begin{array}{l}\text { Coeffi- } \\
\text { cient }\end{array}$ & $p$-value & $\begin{array}{l}\text { Coeffi- } \\
\text { cient }\end{array}$ & $p$-value \\
\hline \multicolumn{9}{|l|}{ Hospital Size } \\
\hline $\begin{array}{l}\text { Hospitals with }<100 \\
\text { beds }\end{array}$ & \multicolumn{8}{|c|}{ Reference } \\
\hline $\begin{array}{l}\text { Hospitals with } \\
100-500 \text { beds }\end{array}$ & 0.41 & .60 & -1.14 & 0.04 & 0.61 & 0.36 & -0.08 & 0.91 \\
\hline $\begin{array}{l}\text { Hospitals with }>500 \\
\text { beds }\end{array}$ & -0.02 & 0.99 & -0.82 & 0.34 & 1.10 & 0.23 & 1.27 & 0.18 \\
\hline \multicolumn{9}{|l|}{ Teaching Status } \\
\hline Teaching Hospitals & 0.41 & 0.53 & 0.40 & 0.31 & 0.23 & 0.57 & -0.54 & 0.21 \\
\hline \multicolumn{9}{|c|}{ Information Technology } \\
\hline $\begin{array}{l}\text { Having at least a } \\
\text { basic EHR system }\end{array}$ & 0.69 & 0.47 & 0.63 & 0.27 & 0.16 & 0.79 & 0.98 & 0.12 \\
\hline $\begin{array}{l}\text { Hospitals using only } \\
\text { one EHR vendor }\end{array}$ & 0.79 & 0.45 & 0.69 & 0.26 & 0.80 & 0.22 & 0.59 & 0.38 \\
\hline $\begin{array}{l}\text { Hospitals Engaging } \\
\text { in the four domains } \\
\text { of interoperability } \\
\text { (Finding, Sending, } \\
\text { Receiving, and Using } \\
\text { Data) }\end{array}$ & 0.19 & 0.76 & 0.41 & 0.26 & 0.15 & 0.70 & 0.13 & 0.74 \\
\hline $\begin{array}{l}\text { Hospitals participat- } \\
\text { ing a Regional } \\
\text { Health Information } \\
\text { Exchange Organiz- } \\
\text { ation }\end{array}$ & 0.09 & 0.91 & -0.54 & 0.26 & 0.08 & 0.8 & -0.63 & 0.23 \\
\hline \multicolumn{9}{|l|}{ Location } \\
\hline $\begin{array}{l}\text { Hospitals located in } \\
\text { an urban setting }\end{array}$ & 0.01 & 0.99 & 0.40 & 0.39 & 0.32 & 0.52 & 0.80 & 0.12 \\
\hline \multicolumn{9}{|c|}{ Hospital Ownership } \\
\hline Private, Non-Profit & \multicolumn{8}{|c|}{ Reference } \\
\hline Public, Non-Federal & -1.56 & 0.26 & 0.17 & 0.83 & 0.27 & 0.75 & -1.65 & 0.07 \\
\hline Federal Hospitals & -2.57 & 0.02 & -1.63 & 0.01 & -0.58 & 0.37 & -0.67 & 0.31 \\
\hline Private, For-Profit & -1.42 & 0.50 & -1.67 & 0.48 & -2.17 & 0.10 & 0.39 & 0.77 \\
\hline \multicolumn{9}{|l|}{ Payment Reform } \\
\hline $\begin{array}{l}\text { Participation in an } \\
\text { Accountable Care } \\
\text { Organization }\end{array}$ & -0.12 & 0.83 & 0.08 & 0.83 & -0.64 & 0.10 & -0.10 & 0.80 \\
\hline $\begin{array}{l}\text { Participation in a } \\
\text { Medical Home }\end{array}$ & 0.87 & 0.16 & 0.27 & 0.45 & -0.40 & 0.30 & 0.09 & 0.82 \\
\hline
\end{tabular}




\section{References}

1. Blumenthal D. Launching HITECH. N Engl J Med 2010; 362(5): 382-385. doi: 10.1056/NEJMp0912825.

2. Bloomrosen M, Starren J, Lorenzi NM, Ash JS, Patel VL, Shortliffe EH. Anticipating and addressing the unintended consequences of health IT and policy: a report from the AMIA 2009 Health Policy Meeting. Journal of the American Medical Informatics Association 2011; 18(1): 82-90. doi: 10.1136/jamia.2010.007567.

3. Ash JS, Berg M, Coiera E. Some unintended consequences of information technology in health care: the nature of patient care information system-related errors. Journal of the American Medical Informatics Association 2004; 11(2): 104-112.

4. Pirnejad H, Niazkhani Z, van der Sijs H, Berg M, Bal R. Impact of a computerized physician order entry system on nurse-physician collaboration in the medication process. International journal of medical informatics 2008; 77(11): 735-744.

5. Quan SD, Wu RC, Rossos PG, Arany T, Groe S, Morra D, Wong BM, Cavalcanti R, Coke W, Lau FY. It's not about pager replacement: An in囚depth look at the interprofessional nature of communication in healthcare. Journal of hospital medicine 2013; 8(3): 137-143.

6. Chiasson M, Reddy M, Kaplan B, Davidson E. Expanding multi-disciplinary approaches to healthcare information technologies: what does information systems offer medical informatics? International journal of medical informatics 2007; 76: S89-S97.

7. Sutcliffe KM, Lewton E, Rosenthal MM. Communication failures: an insidious contributor to medical mishaps. ACADEMIC MEDICINE-PHILADELPHIA- 2004; 79(2): 186-194.

8. Manojlovich M, Adler-Milstein J, Harrod M, Sales A, Hofer TP, Saint S, Krein SL. The Effect of Health Information Technology on Health Care Provider Communication: A Mixed-Method Protocol. JMIR research protocols 2015; 4(2).

9. Adler-Milstein J, DesRoches CM, Furukawa MF, Worzala C, Charles D, Kralovec P, Stalley S, Jha AK. More Than Half of US Hospitals Have At Least A Basic EHR, But Stage 2 Criteria Remain Challenging For Most. Health Affairs 2014. doi: 10.1377/hlthaff.2014.0453.

10. Adler-Milstein J, DesRoches CM, Kralovec P, Foster G, Worzala C, Charles D, Searcy T, Jha AK. Electronic health record adoption in US hospitals: progress continues, but challenges persist. Health Affairs 2015: 10.1377/hlthaff. 2015.0992.

11.DesRoches CM, Worzala C, Joshi MS, Kralovec PD, Jha AK. Small, nonteaching, and rural hospitals continue to be slow in adopting electronic health record systems. Health Affairs 2012; 31(5): 1092-1099.

12. Berg M, Aarts J, van der Lei J. ICT in health care: sociotechnical approaches. Methods Archive 2003; 42(4): 297-301.

13. Aarts J, Ash J, Berg M. Extending the understanding of computerized physician order entry: implications for professional collaboration, workflow and quality of care. International journal of medical informatics 2007; 76: S4-S13.

14.Pirnejad H, Niazkhani Z, Berg M, Bal R. Intra-Organizational Communicationin Healthcare. Methods of Information in Medicine 2008; 47(4).

15. National Nursing Practice Network. Available from: http://www.nnpnetwork.org/.

16. Berwick DM. Launching accountable care organizations - the proposed rule for the Medicare Shared Savings Program. New England Journal of Medicine 2011; 364(16): e32.

17. Care P-CP. Patient-Centered Medical Home. Senate Special Committee on Aging 2007.

18. Jha AK, DesRoches CM, Campbell EG, Donelan K, Rao SR, Ferris TG, Shields A, Rosenbaum S, Blumenthal D. Use of electronic health records in US hospitals. New England Journal of Medicine 2009; 360(16): 1628-1638.

19. Charles D, Swain M, Patel V. Interoperability among US Non-federal Acute Care Hospitals, 2014. 2015.

20.Everson J, Lee S-YD, Friedman CP. Reliability and validity of the American Hospital Association's national longitudinal survey of health information technology adoption. Journal of the American Medical Informatics Association 2014; 21(e2): e257-e263.

21.Gellert George A, Ricardo R, Luke WS. Toward the Elimination of Paper Orders: Ma-naging the Challenge of Low Frequency Physician Users of Computerized Patient Order Entry (CPOE). Appl Clin Inform 2016; 7: 33-42.

22.Patel N, Siegler JE, Stromberg N, Ravitz N, Hanson CW. Perfect Storm of Inpatient Communication Needs and an Innovative Solution Utilizing Smartphones and Secured Messaging. Appl Clin Inform 2016; 7(3): 777-789. doi: 10.4338/ACI-2015-11-RA-0151.

23. Radley DC, Wasserman MR, Olsho LE, Shoemaker SJ, Spranca MD, Bradshaw B. Reduction in medication errors in hospitals due to adoption of computerized provider order entry systems. Journal of the American Medical Informatics Association 2013; 20(3): 470-476. 
24. Keenan G, Yakel E, Lopez KD, Tschannen D, Ford YB. Challenges to nurses' efforts of retrieving, documenting, and communicating patient care information. Journal of the American Medical Informatics Association 2013; 20(2): 245-251.

25. Kossman SP, Scheidenhelm SL. Nurses' perceptions of the impact of electronic health records on work and patient outcomes. CIN: Computers, Informatics, Nursing 2008; 26(2): 69-77.

26. Gagnon MP, Légaré F, Labrecque M, Frémont P, Pluye P, Gagnon J, Car J, Pagliari C, Desmartis M, Turcot L. Interventions for promoting information and communication technologies adoption in healthcare professionals. The Cochrane Library 2009. 
Appendix Table 1 Creation of Technology and Non-IT Communication Practice Indices.

\begin{tabular}{|c|c|}
\hline Question & Responses and Index Scoring \\
\hline \multicolumn{2}{|l|}{ Hardware Index } \\
\hline $\begin{array}{l}\text { What proportion of patient rooms on your } \\
\text { medical-surgical units is equipped with } \\
\text { STATIONARY computer terminals (i.e., work } \\
\text { stations)? }\end{array}$ & $\begin{array}{r}0 \%-74 \%=0.0 \\
75 \%+=1.0\end{array}$ \\
\hline $\begin{array}{l}\text { On your medical-surgical units, are STATION- } \\
\text { ARY computer terminals located in areas } \\
\text { other than the nurses' station(s) or patient } \\
\text { rooms? }\end{array}$ & $\begin{aligned} \text { No } & =0.0 \\
\text { Yes } & =1.0\end{aligned}$ \\
\hline $\begin{array}{l}\text { To what extent in the past year, have you ha- } \\
\text { dissues of user access to STATIONARY com- } \\
\text { puterterminals (e.g., can't find an available } \\
\text { andworking terminal when needed or com- } \\
\text { puter hasbeen locked by another user)? }\end{array}$ & $\begin{aligned} \text { Frequently } & =0.0 \\
\text { Sometimes } & =0.0 \\
\text { Rarely/Never } & =1.0\end{aligned}$ \\
\hline $\begin{array}{l}\text { On your medical-surgical units what propor- } \\
\text { tionof STATIONARY computer terminals are } \\
\text { inworking order the majority of the time: }\end{array}$ & $\begin{array}{r}0 \%-74 \%=0.0 \\
75 \%+=1.0\end{array}$ \\
\hline $\begin{array}{l}\text { Are there any PORTABLE or LAPTOP com- } \\
\text { puters (not including tablets) located on your } \\
\text { medical-surgical units? }\end{array}$ & $\begin{aligned} \text { No } & =0.0 \\
\text { Yes } & =1.0\end{aligned}$ \\
\hline $\begin{array}{l}\text { To what extent in the past year, have you ha- } \\
\text { dissues of user access to PORTABLE or LAP- } \\
\text { TOP(e.g., can't find an available and work- } \\
\text { ingportable or laptop when needed)? }\end{array}$ & $\begin{aligned} \text { Frequently } & =0.0 \\
\text { Sometimes } & =0.0 \\
\text { Rarely/Never } & =1.0\end{aligned}$ \\
\hline $\begin{array}{l}\text { Are there any TABLET computers located on } \\
\text { your medical-surgical units? }\end{array}$ & $\begin{array}{l}\text { No }=0.0 \\
\text { Yes }=1.0\end{array}$ \\
\hline $\begin{array}{l}\text { Do physicians use electronic tablets forcom- } \\
\text { municating with nurses? }\end{array}$ & $\begin{array}{l}\text { No }=0.0 \\
\text { Yes }=1.0\end{array}$ \\
\hline $\begin{array}{l}\text { Do nurses use electronic tablets forcommuni- } \\
\text { cating with physicians? }\end{array}$ & $\begin{aligned} \mathrm{No} & =0.0 \\
\mathrm{Yes} & =1.0\end{aligned}$ \\
\hline $\begin{array}{l}\text { Are there any electronic white boards (i.e., } \\
\text { electronic displays that integrate information } \\
\text { such as bed status, when patients are off } \\
\text { unit for tests, etc.) on your medicalsurgical } \\
\text { units (not white boards in patient rooms)? }\end{array}$ & $\begin{array}{l}\text { All of our medicalsurgical units have electronic white boards }=1.0 \\
\text { Some of our medicalsurgical units have electronic white boards }=1.0 \\
\text { Few of our medicalsurgical units have electronic white boards }=1.0 \\
\text { None of our medicalsurgical units have electronic white boards }=0.0\end{array}$ \\
\hline $\begin{array}{l}\text { Please choose ONE of the following state- } \\
\text { mentsthat best applies to your medical-sur- } \\
\text { gicalunits: }\end{array}$ & $\begin{array}{l}\text { We don't have computers available for work on our medical-surgical } \\
\text { units }=0.0 \\
\text { Physicians work mostly offsite (e.g., remote access from office, home, } \\
\text { other hospital) }=0.0 \\
\text { Physicians work mostly on computers located away from the nursing } \\
\text { unit }=0.0 \\
\text { Physicians work mostly on computers located in the nursing unit }=1.0\end{array}$ \\
\hline What percentage of physicians carry pagers? & $\begin{array}{r}0 \%-74 \%=0.0 \\
75 \%+=1.0\end{array}$ \\
\hline What percentage of nurses carries pagers? & $\begin{aligned} 0 \%-24 \% & =0.0 \\
25 \%+ & =1.0\end{aligned}$ \\
\hline
\end{tabular}


Appendix Table 1 Continued

Question
Does your hospital have a paging website
(that allows for web messaging), a tele-
phone paging system, or both? Please select
only ONE of the following choices:

Do physician / nurse pagers have the capability to sendas well as receive text messages?

Do physician / nurse pagers have the capability todisplay text?

\section{Software Index}

If hospital is a respondent to AHA IT supplement and has EHR data:

Do physicians and nurses use an email programwithin the electronic health record system tocommunicate with each other (i.e., physician tonurse? nurse to physician)?

Do physicians and nurses use an email programseparate from the electronic health recordsystem to communicate with each other (i.e.,physician to nurse? nurse to physician)?

Do physicians use the computerized providerorder entry (CPOE) function as a way tocommunicate with nurses (e.g., when a nursepages a physician with a request, the physicianenters an order in CPOE instead of answeringthe nurse directly)?

Do nurses receive notification through thecomputerized system when a physician entersan order?

Is there a way for nurses to acknowledge receipt of an order in the computerized system?

Is there a way for nurses to document in thecomputerized system when an order has beencarried out?

Do physicians and nurses have access to thesame or different information when usingcomputerized functions (e.g., CPOE)?

\section{Responses and Index Scoring}

Paging website (needs internet connection. Allows input of text as well as numbers) $=0.0$

tem) $=0.0$

Both paging website and telephone paging systems $=0.0$

Nurse AND Physician No $=0.0$

Nurse OR Physician Yes $=0.75$

Nurses AND Physician Yes $=1.0$

Nurse AND Physician No $=0.0$

Nurse OR Physician Yes $=0.25$

Nurses AND Physician Yes $=0.5$

Some information is accessible to nurses only $=0.0$

Some information is accessible to physicians only $=0.0$

Physicians and nurses have access to the same information $=1.0$ 
Appendix Table 1 Continued

\section{Question}

Do physicians and nurses communicate viasome other computer application such asmiddleware? Middleware is software thatenables communication between an operatingsystem and applications in a distributedcomputing system (e.g., smart phone apps thatlet physicians know nurse staff assignments fora shift, or that send patient alarms to physicianand/or nurse smart phones).

What proportion of STATIONARY computer terminals allows internet access?

\section{Telephony Index}

On medical-surgical units, are landlinetelephones placed in any location not includingthe nurses' station or patient rooms?

Do the landline telephones on your medicalsurgical units have texting functions?

If nurses have individual telephones, please select ONE of the following statements that best applies to your medical-surgical units:

To what extent in the past year, have you hadissues of user access to landline telephones(i.e., can't find an available and workingtelephone when needed)?

On medical-surgical units, do nurses use cellular telephones for work-related purposes?

On medical-surgical units, do physicians usecellular telephones for work-related purposes?

\section{Communication Practices Index}

Physicians use face-to-face communication withnurses.

Nurses use face-to-face communication withphysicians.

Nurses communicate with a physician extender(nurse practitioner or physician assistant) beforecontacting a physician.

Physicians give verbal orders to nurses.

\section{Responses and Index Scoring}

We don't have any middleware $=0.0$

Rarely/Never $=0.0$

Sometimes $=1.0$

Regularly $=1.0$ $\begin{aligned} 0 \%-74 \% & =0.0 \\ 75 \%+ & =1.0\end{aligned}$

Rarely (less than once/week) $=0.0$

Sometimes (at least once/week) $=0.0$

Regularly (> once/week) $=0.0$

All the time (daily) $=1.0$

Rarely (less than once/week) $=0.0$

Sometimes (at least once/week) $=0.0$

Regularly ( $>$ once/week) $=0.0$

All the time (daily) $=1.0$

Rarely (less than once/week) $=0.0$

Sometimes (at least once/week) $=0.0$

Regularly (> once/week) $=1.0$

All the time (daily) $=1.0$

Rarely (less than once/week) $=0.0$

Sometimes (at least once/week) $=1.0$

Regularly ( $>$ once/week) $=1.0$

All the time (daily) $=1.0$ 
Appendix Table 1 Continued

\begin{tabular}{|c|c|}
\hline Question & Responses and Index Scoring \\
\hline $\begin{array}{l}\text { Bedside nurses participate in patient care } \\
\text { rounds. }\end{array}$ & $\begin{array}{r}\text { Rarely (less than once/week) }=0.0 \\
\text { Sometimes (at least once/week) }=0.0 \\
\text { Regularly }(>\text { once/week) }=0.0 \\
\text { All the time (daily) }=1.0\end{array}$ \\
\hline $\begin{array}{l}\text { Please choose ONE of the following state- } \\
\text { mentsthat best applies to your medical-sur- } \\
\text { gical units: }\end{array}$ & $\begin{array}{l}\text { Nurses generally prefer to page physicians to a phone covered by a } \\
\text { clerk }=0.5 \\
\text { Nurses generally prefer to text physicians }=0.5 \\
\text { Nurses generally prefer to page physicians to another phone (e.g., their } \\
\text { own phone, a phone close to a patient's room) }=1.0 \\
\text { Nurses generally prefer to call physicians' cell phones }=1.0\end{array}$ \\
\hline $\begin{array}{l}\text { Please choose ONE of the following state- } \\
\text { mentsthat best applies to your medical-sur- } \\
\text { gical units: }\end{array}$ & $\begin{array}{l}\text { Physicians generally prefer to page nurses to a phone covered by a clerk } \\
=0.5 \\
\text { Physicians generally prefer to text nurses }=0.5 \\
\text { Physicians generally prefer to page nurses to another phone (e.g., their } \\
\text { own phone, a phone close to a patient's room) }=1.0 \\
\text { Physicians generally prefer to call nurses' cell phones }=1.0\end{array}$ \\
\hline
\end{tabular}

